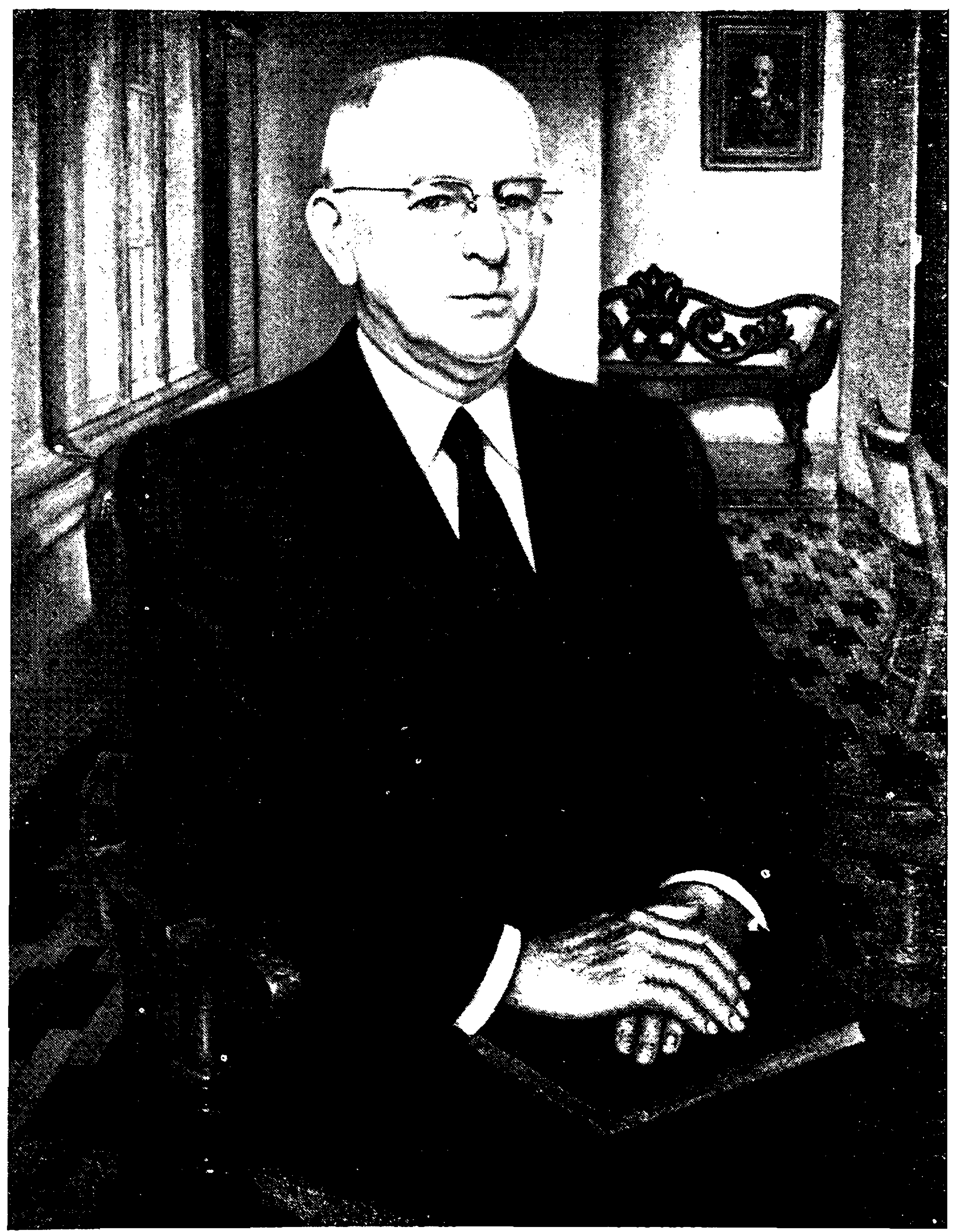

Prof. Dr. Henrique de Beaurepaire Aragão Rcproduçío do quadro a óleo de $D$. Ismaelovitoh, 1949 


\section{MEMÓRIAS}

DO

\section{NSTITUTO OSWALDO CRUZ}

Tomo 53 Fascículos 2-3 e 4 Junho a Dezembro de 1955

Êste Volume das Memórias do Instituto Oswaldo Cruz é publicado em homenagem ao Professor Dr. Henrique de Beaurepaire Aragão, por ccasião do qüinquagésimo aniversário de suas ațividades oficiais.

Iniciou o Dr. Aragão sua carreira científica em 1903, como estagiário, ao lado de Oswaldo Cruz, cuja brilhante trajetória então começava. Em mais de cinqüenta anos de labor científico, espraiou o Dr. Henrique Aragão seu espírito curioso sôbre variados setores da Biologia. Suas contribuições em Protozoologia e em Vírus, foram pioneiras em nosso meio, merecendo especial realce sua descoberta do ciclo evolutivo do Haemoproteus columbae, e a descrição dos corpúsculos do alastrim, da varicela e do mixoma dos coelhos. Dedicou-se, também, à sistemática dos ixodídeos, descrevendo várias espécies novas e verificando a existência de multiplicação partenogenética nestes acarianos, um fato até então ainda não verificado. Ao cabo de tantos anos dedicados à ciência, passados todos êles, pode dizer-se, no quadro esplêndido do Instituto Oswaldo Cruz, continua o Dr. Henrique Aragão suas pesquisas, com o mesmo interêsse dos primeiros anos, servindo à Instituição que ajudou a criar e a projetar no cenário científico mundial. 


\title{
Notas bio-bibliográficas do Prof. Dr. Henrique de Beaurepaire Āragão, Diretor Emérito do Instituto Oswaldo Cruz
}

\author{
pelo
}

\section{Dr. F. Nery-Guimarães}

O Dr. H. B. Aragão nasceu em 21 de dezembro de 1879 , à rua da Praia, em Niterói (Estado do Rio de Janeiro). Há muito a abertura de uma avenida sacrificou a casa onde nasceu. Foram seus pais o Dr. Francisco Pires de Carvalho Aragão e D. Elisa de Beaurepaire Rohan AragÃo. Fêz estudos de humanidades no Rio de Janeiro, no Instituto Dr. João Kopke e no Externato do Ginasio Nacional, hoje Colégio Pedro II, onde os concluiu em fins de 1898. Diplomou-se cm 1904, pela Faculdade de Medicina do Rio de Janeiro. Ainda estudante, no $5 .^{\circ}$ ano médico, ingressou em Manguinhos, como estagiário (1903) . Lá fôra levado por WALDEMAR Schiller, seu amigo e colega, que já freqüentava o Instituto e o apresentou a Oswaldo Cruz. Desde essa época, Aragão vinculou-se ao Instituto; nêle fazendo sua tése de doutoramento, que defendeu em 1905, entrando, então, oficialmente para a instituição como Assistente.

Falar de Henrique Aragão é, também, falar da história de Manguinhos, pois foi êle um dos poucos que lá chegaram na hora primeira. Cercando a figura ímpar de Oswaldo, estavam FigueIREdo Vasconcellos, Rocha lima, Carlos Chagas, Ezequiel Dias, Cardoso Fontes, Alcides Godoy e Henrique Aragão. Logo em seguida chegavam Arthur Neiva e Gomes DE Faria. Outros sábios ilustres chegaram depois.

Naquela época para tão poucos, era imensa a tarefa a cumprir. Mas. o entusiasmo de todos e o desejo de cada um de corresponder à confiança do Mestre, operavam milagres. Naquela velha e acanhada casa da Fazenda de Manguinhos, quase em ruínas, só havia dois laboratórios para o trabalho em comum, dois microscópios e o material estritamente necessário. Apesar disso, tudo corria bem, e ARAGÃo logo se adaptou às atividades da nova Escola de Medicina Experimental. Era um grupo de jovens a quem os costumes da época - e mais do que isso, o idealismo e o sentido de uma tarefa nobilitante - davam a aparência de homens maduros. O Mestre contava 30 anos, e menos idades tinham os discípulos.

* Recebido para publicação a 26-8-1955, con uma futografia. 
De início, não havia ambiente para estritas especulações e ARAGão, como os demais, se ocupava um pouco de tudo que dizia respeito aos serviços técnicos do Instituto. Ao mesmo tempo que realizava suas primeiras investigações científicas, fazia bacteriologia geral, preparava sôros e vacinas, estudava espiroquetas e protozoários de vida livre e sanguícolas, classificava carrapatos transmissores de doenças ou apenas parasitos e investigava os corpúsculos dos virus, naquela época bem pouco credenciados, nem de longe se suspeitando da importância que iriam ter na nosologia moderna. Tratando, assim, de tão variados assuntos, adquiriu Aragão uma ampla vista panorâmica em vários campos da biologia e, particularmente, da microbiologia, dando à publicidade vários trabalhos científicos. Data dessa época a sua descoberta do ciclo do Haemoproteus columbae, trabalho magistral que contrariava as idéias de Schaudinn - a máxima autoridade científica de então - e cuja repercussão na protozoologia foi tamanha, a ponto de podermos considerá-lo como o marco inicial da descoberta do ciclo exoeritrocitário dos plasmódios.

Da importância do trabalho que realizava êsse grupo de jovens pesquisadores, orientados por Oswaldo CRUz, soube-o o país quando da Exposição Internacional de Berlim, em 1907. Tal foi o sucesso do Brasil, que lhe foi conferido o máximo laurel. Nessa exposição foram mostradas as realizações de Oswaldo no campo da saúde pública e os primeiros trabalhos científicos de Manguinhos.

Foi então, quando sábios europeus se interessaram pelo novo Instituto e pelo campo de pesquisa que representava o nosso país, e a convite de Oswaldo Cruz vieram a Manguinhos Prowazek, Hartmann, Gremsa e outros abalisados mestres da medicina experimental.

Aragão colaborou com Prowazek durante os seis meses que êsse grande pesquisador estêve no Brasil. E, quando do seu retôrno à Europa em fevereiro de 1909, acompanhou-o em viagem de aperfeiçoamento. No velho continente, estudou na Alemanha, no Instituto Zoológico de Munique, dirigido por R. HerTwig, e sob a orientação de R. GoldsCHMidT. Estudou também na Estação de Hidrobiologia Marinha de Villefranche, dirigida por DAVIDOFF e, de volta ao Brasil, em setembro de 1910, retornou ao seu trabalho de Manguinhos, onde se encontra até hoje.

Se pudéssemos retrogradar no tempo, seria interessante agora, nesta época de grandes progressos quimioterápicos e imunobiológicos, reportarmo-nos àquela fase pioneira do princípio do século .

Veríamos ARAGÃo preparando sua vacina contra a espiroquetose das aves, e empregando pela primeira vez o formol como esterilizante de vacinas. A técnica nos trouxe grandes aperfeiçoamentos, sem dúvida, mas o formol continua em uso, sendo interessante assinalar o seu emprêgo, ainda hoje, em vacinas antitíficas e na moderna anti-polio de SALK.

As incursões de ARAGÃo na nascente virologia, levaram-no a determinar os agentes etiológicos do alastrim, da varicela e do mixoma dos coelhos, assim como a transmissão desta última doença pelas pulgas. Mais tarde, no estudo do virus amarílico, muito trabalhou. Estabeleceu a 
identidade dos virus africano e americano; imaginou a prova de proteção em Rhesus para o diagnóstico retrospectivo da febre amarela, o qual de início foi o empregado em trabalhos epidemiológicos no Brasil; verificou que a transmissão da moléstia estava relacionada às condições de vida dos transmissores, exigindo o Aedes aegypti temperatura mais elevada para permitir a evolução do virus, ao contrário dos mosquitos silvestres. adaptados às temperaturas mais baixas das matas.

$\mathrm{Na}$ protozoologia, de cuja seção foi o organizador en Manguinhos. pesquisou vários setores, descrevendo novas espécies de amebas e outros protozóarios, assim como as formas evolutivas dos gametas do Plasmodium falciparum. Em 1921, verificou a transmissão da leishmaniose muco- cutânea pelo Phlebotomus intermedius, no Brasil, assunto que, nesse tempo, também era investigado em vários centros de Medicina experimental, para outras espécies dêsses psicodideos. Estudou, ainda, ARAGÃo os Ixodídeos, descrevendo várias espécies novas e verificando a existência de multiplicação por partenogenese nesses acarianos. Pesquisou o ciclo evolutivo dos Blastocystis, confirmando e ampliando as verificações de AlEXEIEFF sobre a sua natureza blastomicetica, sem relação alguma portanto com os flagelados, como admitiram vários autores.

Da sua personalidade de mestre ressalta, sobretudo, a capacidade de estimular os jovens de Manguinhos, que dêle se aproximam para ouvir conselhos ditados por uma longa experiência nos campos da biologia; $e$ nada o alegra tanto como sentir nesses moços uma decidida vocação para a investigação científica. Notável também - hoje como outrora - é o seu interêsse por tudo que diz respeito a Manguinhos; interêsse que vae dos laboratórios e biotérios de criação de animais de experiência, ao parque botânico, quase todo por êle organizado, e com cuja maioria de exemplares está familiarizado.

A investigação científica pura conduz, não raro, o pesquisador a encontrạ soluções de alto valor prático para dados problemas. Assim é que ARAGÃo, no decurso de suas pesquisas sôbre a mixomatose dos coelhos, impressionado com a ação letal dessa doença para êsses roedores, vislumbrou a possibilidade do seu emprêgo como arma biológica de combate ao bilhão ou mais de coelhos que, destruiam impiedosamente as pastagens e culturas agrícolas na Austrália, afetando profundamente a economia agropecuária dêsse continente. Depois de uma série de experiências que robusteceram sua opinião a respeito do possível sucesso dessa luta biológica, dirigiu-se AraGÃo às autoridades competentes do Commonwealth da Austrália. Sugeriu-lhes a luta biológica contra a praga dos coelhos, com o uso da mixomatose, de vez que todos os demais meios de destruição dêsses animais, usados até então, não davam resultados suficientemente eficazes. A sugestão de H. ArAGÃo foi aceita pelas autoridades australianas, às quais mandou o virus da mixomatose. Longos anos se passaram, porém, antes que os resultados das experiências com êsse virus viessem coroar as esperanças depositadas na mixomatose. Não desanimaram, porém, os australianos, nem $\mathrm{H}$. ARAGÃo perdia a confiança no sucesso da sua sugestão. Êste chegou, finalmente, e de modo espetacular, 
a partir de 1950, quando surgiu na Australia uma incrível epizootia de mixomatose, que tão mortífera quão ràpidamente se disseminou por centenas de milhares de milhas quadradas do seu território leste e sul. Essas mortíferas epizootias vem se repetindo no verão quando abundam os insetos sugadores de sangue, que são seus principais veiculadores. Avalia-se que em consequiência delas já foram destruídos cerca de três quartos da população de coelhos da Austrália e a agricultura tomou novo surto. Calcula-se que com esta destruição maciça de coelhos a Austrália já ganhou dezenas de milhões de libras esterlinas. E, assim, mais uma vez, uma investigação científica de caráter puramente especulativo abriu caminho para a solução de um problema de grande valor prático para a economia de um povo.

No seu longo período de vida, Henrique Aragão viu o Instituto Oswaldo Cruz crescer do quase nada, até se tornar a grandiosa instituição que hoje representa - uma verdadeira universidade científica, com cêrca de 150 pesquisadores e dezenas de seções que se ocupam dos mais variados assuntos da Microbiologia, Zoologia Médica, Hidrobiologia, Botânica Médica, Fisiologia, Protozoologia, Química, Endocrinologia, Higiene, Doenças Tropicais, Patologia, Micologia, Hematologia, Virologia e Riquetsioses, além de produzir amplamente sôros e vacinas e ministrar vários cursos de especialização.

Iniciando sua carreira $\mathrm{em}$ Manguinhos, como estagiário, ARAGÃo passou a Assistente e a Chefe de Serviço e, mais tarde, a Biologista com as vantagens de Professor das Universidades Federais. Por fim, exerceu o cargo de Diretor do Instituto (1942-1949). Em 1950, aposentou-se por limite de idade. Como um dos fundadores do Instituto, Ioi-lhe conferido, por Decreto do Govêrno, o título de Professor do Instituto Oswaldo Cruz e, após sua aposentadoria, recebeu ainda o título de Diretor Emérito do Instituto Oswaldo Cruz, por Decreto do Presidente Getúlio Vargas e do Ministro Miguel Couto Frlho.

Durante sua gestão de 7 anos como Diretor do Instituto Oswaldo Cruz, conseguiu H. Aragão quintuplicar suas verbas, instalar divisões e seções científicas e técnicas, aumentar muito o número de pesquisadores, organizar centros para o estudo da moléstia de Chagas, em Minas Gerais, para investigações sôbre bouba, no Estado do Rio e para a profilaxia da esquistossomose, em Pernambuco. Promoveu, ainda, numerosas excursões científicas para estudos de hidrobiologia marinha, zoologia e botânica médicas, para investigações nosológicas, ecológicas e epidemiológicas diversas.

Ainda nesse período, promoveu a construção no Instituto de um amplo hospital e grandes prédios para as Divisões de Patologia e de Higiene e para as seções de Endocrinologia e Hematologia, para os Cursos, para estudos de Biologia, para Refeitório do pessoal, levantou novos andares no pavilhão de química e no biotério, além de instalações novas ou ampliações nas oficinas e outros ser viços auxiliares do Instituto.

Henrique Aragão dirigiu o Serviço Especial de Febre Amarela de São Paulo (1937-1938); fêz parte do Conselho Econômico do Estado do Rio de Janeiro, durante a Interventoria do Comandante ARY PARREIRAs; 
foi membro do Conselho Técnico da Prefeitura do Distrito Federal, quando Prefeito o Dr. Pedro Ernesto; e fêz parte do Conselho Central da Fundação da Casa Popular. Durante três anos foi Vice-Presidente do Instituto Brasileiro de Educação, Ciência e Cultura (IBECC), órgão governamental ligado à UNESCO. Presentemente é membro do Conselho Nacional de Saúde, do Ministério da Saúde, e foi Chefe da Seção de Etiopatogenia da Lepra, do Centro Internacional de Leprologia.

ARAGÃo representou o Instituto Oswaldo Cruz em vários congressos médicos e de higiene e foi Presidente da Comissão Organizadora do $\mathrm{V}$ Congresso Internacional de Microbiologia (1950).

Foi Professor dos Cursos do Instituto Oswaldo Cruz por muitos anos, assim como Professor do Curso de Malária da Fundação Rockefeller e do Curso de Saúde Pública do Ministério da Educação e Saúde.

Em Manguinhos, foi o organizador da Seção de Protozoologia e da Estação de Hidrobiologia Marinha (Ilha do Pinheiro) .

Henrique Aragão é detentor da medalha Nocht, conferida pelo Instituto de Medicina Tropical de Hamburgo, por seus trabalhos sôbre Medicina Tropical. Possui, também, a Comenda da Cruz Vermelha Alemã, por seus méritos científicos, e faz parte de numerosas sociedades científicas nacionais e internacionais.

Suas publicações no Brasil e no estrangeiro excedem a cento e cinqüenta.

Aposentado há 5 anos, continua trabalhando em seu laboratório em Manguinhos, fiel ao lema de seu Mestre: "Nada resiste ao Trabalho". E a quem o vê, hoje, curvado ao microscópio, como há meio século, ocorre o pensamento de que, às vêzes, o Homem vence o Tempo...

\section{Lista das Sociedades Cientificas às quais pertence o Dr. Henrique de Beaurepaire Aragão}

Membro de Honra da Societé de Pathologie Exotique de Paris Membro Correspondente da Société de Biologie de Paris Membro Correspondente da Société Belge de Médicine Tropicale Membro Honorário da Academia Nacional de Medicina Membro Honorário da Academia Nacional de Medicina Militar Membro Honorário da Sociedade Brasileira de Entomologia Presidente de Honra da Sociedade Brasileira para o Progresso da Ciência Membro Honorário da Sociedade Brasileira de Patologia Membro da Sociedade Argentina de Patologia y Epidemiologia Membro da Sociedade Brasileira de Higiene Membro da Sociedade Brasileira de Biologia Membro da Royal Society of Tropical Medicine and Hygiene de Londres Membro da Society of American Bacteriologists Membro da Sociedade Entomológica do Brasil 


\section{RELAÇÃO DOS TRABALHOS PUBLICADOS PELO DR. HENRIQUE DE BEAUREPAIRE ARAGÃO}

1) Ensaios de sôrotherapia nas molestias produzidas por germens não cultivaveis

Tése - Rio - 1905.

2) Nova tecnica para o diagnostico da "peste".

(com Lima, $\mathrm{H}$. de Rocha)

Annuario do Brazil-Medico, 1906.

3) Sobre o cyclo evolutivo no halteridio do pombo.

Brazil-Medico, 1907, Anno 21, pp. 141 e 301.

4) Untersuchungen ueber die Variola.

(com Prowazek)

Muench. med. Wcchenschr. 1908, Jahr. 55, pp. 2265-2266.

5) Ueber den Entwicklungsgang und die Uebertragung von Haemoproteus columbae.

Archiv f. Protistenk., 1908 Bd. 12, pg. 157.

6) Algumas novas especies de carrapatos brazileiros: - Haemaphysalis kochi, Amblyomma lutzi, $A$. brasiliensis, $A$. parvum.

Brazil-Medico, 1908, Anno 22, pp. 111.

7) Mais um novo carrapato brazileiro: - Amblyomma pseudo-concolor.

Brazil-Medico, 1908, Anno 22, pp. 431.

8) Sobre o cyclo evolutivo e a transmissão do Haemoproteus columbae.

Rev. Med. de S. Paulo, 1908, Anno 11, n. ${ }^{\circ}$ 20, pp. 416.

9) Weitere Untersuchungen ueber Chlamydosoen.

(com Prowazek)

Muench. med. Wochenschr. 1909. Jahr. 56, pp. 645-646.

10) Mais uma espécie de carrapato brazileiro: - Amblyomma mantiquirense. Brazil-Medico 1908, Anno 22, pp. 431-432.

11) Relatorio a respeito dos trabalhos executados na invernada dos Affonsos na Brigada Policial, apresentado ao Dr. Oswaldo Cruz, 1909, 10 de Junho.

12) Sobre a Amoeba diplomitotica n. sp., Contribuição para o estudo da divisão nuclear nas amebas.

Mem. Inst. Oswaldo Cruz, 1909, T. 1, pp. 33-42.

13) Contribuição para o estudo dos parasitas intraglobulares dos Lacertidas. Plasmodium diploglossi n. sp.; Plasmodium tropiduri, n. sp.

(com Neiva, Arthur)

Mem. Inst. Oswaldo Cruz, 1909, T. 1, pp. 44-50.

14) Estudos sobre a variola.

(com Prowazek, S. von)

Mem. Inst. Oswaldo Cruz, 1909, T. 1, pp. 147-158.

15) Pesquizas sobre a Polytomella agilis n. g., $\mathrm{n}$. sp.

Mem. Inst. Oswaldo Cruz, 1910, T. 2, pp. 42-57.

16) A prcposito do alastrim. (Comunicação preliminar) Brazil-Medico, 1911, Anno 25, pp. 101-103.

17) Sorotherapia e vaccinação na espiroquetose das gallinhas.

Mem. Inst. Oswaldo Cruz, 1911, T. 3, pp. 3-39.

18) Observações sobre algumas hemogregarinas das aves.

Mem. Inst. Oswaldo Cruz, T. 3, pp. 54-64.

19) Notas sobre Ixódidas brazileiros.

Mem. Inst. Oswaldo Cruz, 1911, T. 3, pp. 145-194.

20) Estudos sobre alastrim.

Mem. Inst. Oswaldo Cruz,, 1911, T. 3, pp. 309-319.

21) Sobre o microbio do myxoma dos coelhos.

Brazil-Medico, 1912, Anno 26, pp. 471-473.

22) Sobre uma nova entamoeba humana (Entamoeba braziliensis n. sp.). Brazil-Medico, 1912, Anno 26, pp. 61-62.

23) Sobre o "Granuloma venereum" e o seu microbio (Nota prévia). (com Vianna, Gaspar)

Brazil-Medico, 1912, Anno 26, pp. 283-285. 
24) Nota sobre Ixódidas collecionadas durante a expedição do Snr. Coronel Rondon nos Estados de Goyaz e Matto Grosso, pelo Snr. Dr. Murillo de Campos. medico da expedição.

Brazil-Medico, 1912, Anno 26, pp. 428-430.

25) Contribuição para a systematica e biologia dos Ixódidas. Partenojenese em carrapatos. Amblyomma agamum n. sp

Mem. Inst. Oswaldo Cruz, 1912, T. 4, pp. 96-118.

26) Noticia sobre o "Nyctotherus cordiformis" Stein.

Mem. Inst. Oswaldo Cruz, 1912, T. 4, pp. 125-129.

27) Sobre o tratamento do "Granuloma venereum" pelo tartaro emetico. (com Vianna, Gaspar)

Brazil-Medico, 1913, Anno 27, pp. 41-42 .

28) Sobre um novo treponema encontrado em ulceras: Treponema minimum n. $\mathrm{sp}$.

(com Vianna, Gaspar)

Brazil-Medico, 1913, Anno 27, pp. 61-62.

29) Pesquizas sobre a natureza dcs anaplasmas. (com Dias, Ezequiel)

Brazil-Medico, 1913, Anno 27, pp. 151-153.

30) Nota sôbre as schizogonias e gametogonias dos trypanosomas.

Brazil-Medico, 1913, Anno 27, pp. 271-272.

31) Pesquizas sobre o "Granuloma venereum". (com Vianna, Gaspar)

Mem. Inst. Oswaldo Cruz, 1913, T. 5, pp. 211-236.

32) Nota sobre algumas colleçōes de carrapatos brazileiros.

Mem. Inst. Oswaldo Cruz. 1913, T. 5, pp. 263-270.

33) Sobre a Entamoeba brasiliensis.

Mem. Inst. Oswaldo Cruz, 1914, T. 6, pp. 5-10.

34) Fesquizas sobre a natureza dos anaplasmas.

(com Dias, Ezequiel)

Mem. Inst. Oswaldo Cruz, 1914, T. 6, pp. 231-245.

35 ) Dr. S. Von Prowazek. Necrologia.

Arch. Bras. Med., Rio 1915, Anno 5, pp. 167-169.

36) Ixódidas. Relatório n. 27 da Commissão Rondon, 1916.

37) Copromastix prowazeki n. g. n. sp. (nota prévia).

Brazil-Medico, 1916, Anno 30, pp. 49.

38) Pesquizas sobre o "Haemoproteus columbae".

Brazil-Medico, 1916, 30, Nos. 45 e 46, pp. 353 e 36.

39) Consideraçōes sobre o papel dos mosquitos na transmissão da lepra.

1. ${ }^{\text {a }}$ Conferencia Sul-Amer. Hyg. Microb. \& 1916, p. 125.

40) Pesquizas sobre o Copromastix prowazeki $\mathrm{n}$. $\mathrm{g}_{\text {., }} \mathrm{n}$. $\mathrm{sp}$. Mem. Inst. Oswaldo Cruz, 1916, 8, n. 2, pp. 64-67.

41) Algumas observacõos relativas ás endamebas dysentericas. Brazil-Medico, 1917, 31, n. 13 e 14, pp. 105 e 113.

42) Espiroquetose e treponemose das gallinhas.

Rev. Zootechnia e Veterinaria, 1917, 7, n.o 1, pp. 3-10.

43) Sobre a presença do Espirocheeta ictero-hemorrhagiae nos ratos no Rio de Janeiro.

Erazil-Medico, 1917, 31, n.ò 39, pp. 329.

44) Notes on "Granuloma venereum".

New Orleans med. \& Trop. Journal, 1917, 70, p. 369.

45) Febre amarela e ictericia epidemica. Orientação para uma therapeutica racional.

Brazil-Medico, 1917, 31, n.o 40, p. 409.

46) Scme observations on the dysenterial endameba.

New Orleans med. \& Trop. Journal, 1917, 70, pp. 374.

47) Considerações sobre a nomenclatura das endamebas parasitas do homem. Annaes $1 .^{\circ}$ Congr. Med. Paulista, 1917, 2, p. 287.

48) Algumas observações relativas às endamebas dysentericas.

Rev. Soc. Bras. Sci., 1917, n. ${ }^{\circ}$ 1, p. 59. 
49) Problema de prophylaxia rural.

Relatorio apresentado à Sociedade Nacional de Agricultura, em 9-10-1918 Imprensa Nacional 1918.

50; A proposito da grippe (Nota prévia) .

Brazil-Médico, $1918,32, \mathrm{~N} .{ }^{\circ} 45$, p. 353

51) Notas ixodidologicas.

52) Theodoro Bayma.

Necrologia.

Brazil-Medico, 1918, 16 de novembro.

53) Classificação dos hemosperidios.

Mem. Inst. Butantan, 1918.

54) Considerações sobre as endamebas parasitas de intestino humano.

Conferencia Soc. Med. e Cir. S. Paulo, 1918, 3 de março.

55) Novo methodo para facilitar o diagnostico e a conservação os embryões de filaria no sangue e de parasitas nas fezes.

Brazil-Medico, 1918, 33, n.o 2, p. 9.

56) Breves consideracooes sobre a babesiose e a anaplasmose bovina.

Brazil-Medico, 1918, 33, n. ${ }^{\circ}$ 2, p. 9.

57) Primeiros resultados do tratamento da febre amarella pelo neosalvarsan. (Nota prévia)

Brazil-Medico, 1919, 33, n.o 26, p. 201.

58) Sobre o microbio no "Granuloma venereum".

Brazil-Medico, 1919, 33, n.o 10, p. 74.

59. Alguns problemas relativos ás endemias ruraes no Brazil.

Discurso Soc. Med. e Cir. Rio, 1919, 15 de julho.

60) Transmissão do virus do myxoma dos coelhos pelas pulgas.

Brazil-Medico, 1920, 34, n. ${ }^{\circ} 46$, p. 753.

61) Sobre os Ornithodores rostratus Arag.

Arch. Escola Sup. Agricult. 1920.

62) A proposito da Polytomella agilis Arag

Brazil-Medico, 1921, 35, n. ${ }^{\circ}$ 9, p. 107.

63) Transmissão da leishmanicse no Brazil pelo Phlebotomus intermedius.

Brazil-Medico, 1922, 36, n. ${ }^{\circ} 11$, p. 129.

64) Estudos sobre os Blastocystis.

Mem. Inst. Oswaldo Cruz, 1922, 15, n. ${ }^{\circ}$ 1, p. 240.

65) Ornithodoros braziliensis, $\mathrm{n}$. sp.

Brazil-Medico, 1923, 37, n.o 2, p. 20.

66) Pesquizas sobre Blastocystis.

Brazil-Medico, 1923, 37, n. ${ }^{\circ}$ 5, p. 58.

67) Leishmaniose tegumentar e sua transmissão pelos phlebotomos.

Mem. Inst. Oswaldo Cruz, 1927, 20, n. ${ }^{\circ}$ 2, p. 177.

68) Myxoma dos coelhos.

Mem. Inst. Oswaldo Cruz, 1927, 20, n.o 2, p. 225.

69) Sur l'évolution du Homoproteus columbae et du Trypanosoma hanai dans la Lynchia maura Bigot.

C. R. Soc. Bicl., 1927, 97, n. 25, p. 827.

70) Sur un flagellé du latex de Maniot palmata, Phytomonas françai, $\mathrm{n}$. sp. C. R. Soc. Biol., 1927, 97, p. 1077.

71) Palestra sobre leishmaniose.

Sciencia Médica, Rio 1927,5, n. ${ }^{\circ} 3$, p. 121.

72) O hematozoario do paludismo.

Arch. Bras. Med., Rio 1927, 17, n. ${ }^{\circ}$ 4, p. 260.

73) Ueber Phytomonas Françai (einen neuen Flagellaten des Milchsaftes von Maniot palmata).

Abhandlungen aus dem Gebiete der Auslandskunde, Hamburgische Universitat, Band 26, 2 (Fetschrift Nocht) 1927.

74) Transmissão da leishmaniose pelos Phlebotomos.

A Folha Medica, Rio 1928, Anno 9, n.o 2, p. 13. 
75) Relatório sobre as theses apresentadas sobre o thema $\mathrm{V}$ no $4 .^{\circ}$ Congresso Brasileiro de Hygiene.

Science Médica, Rio, 1928, 6, n.o 4, p. 160.

76) Observações sobre a febre amarella no Brasil.

Brazil-Médico, 1928, 42, n.o 27, p. 727.

77) Relatorio a respeito de algumas pesquizas sobre a febre amarella.

Mem. Inst. Oswaldo Cruz, 1928, suppl. n.o 2, p. 23.

78) Recherches sur la fièvre Jaune.

C. R. Soc. Biol., 1928, 99, n. ${ }^{\circ} 30$, p. 1341

79) Recherches sur la fièvre Jaune.

Bull. Office Internat. Hyg. Publique, 1928, 20, n. ${ }^{\circ} 10$, p. 1584.

80) Possibilidade da infecção de Aedes aegypti machos com virus da febre amarella.

Brazil-Medico, 1929, 43, n. ${ }^{\circ} 24$, p. 671.

81) Sobre a transmissão de virus da febre amarella pelas fezes de mosquitos infectados.

(com Lima, A. da Costa)

Brasil-Medico, 1929,43, n. ${ }^{\circ} 24$, p. 669

82) Sobre a transmissão do virus da febre amarella pelas fezes de mosquitos infectados.

(com Lima, A. da Costa)

Mem. Inst. Oswaldo Cruz, 1929, Suppl. n. 8 8, p. 101.

83) Febre amarella experimental do Brasil.

Brasil-Medico, 1929, 43, n. ${ }^{\circ}$ 30, p. 849.

84) Sobre a infecção do $M$. rhesus pela deposição de fezes de mosquitos infectados sobre a pele ou na conjunctiva ocular integras. (com Lima, A. da Costa)

Mem. Inst. Oswaldo Cruz, 1929, Suppl. n.o 9, p. 133.

85) Possibilidade da propagação directa da febre amarela de Stegomyia a "Aedes aegypti" sem intervenção do homem.

Brasil-Medico, 1929,43, n. ${ }^{\circ} 31$, p. 885.

86) Sobre o tempo necessario para que stegomyias infectados excretem fezes virulentas.

(com Lima, A. da Costa)

Mem. Inst. Oswaldo Cruz, 1929, Suppl. n. 9 9, p. 139.

87) Infecção de Aedes aegypti macho e possibilidade da propagação da febre amarela de Stegomyia a Stegomyia sem passagem pelo homem.

Mem. Inst. Oswaldo Cruz, 1929, Suppl. n. ${ }^{\circ}$ 9, p. 190.

88) Sobre o poder infectante da haemolympha dos mosquitos contaminados com o virus da febre amarela.

(com Lima, A. da Costa)

Mem. Inst. Oswaldo Cruz, 1929, Suppl. n. ${ }^{\circ} 10$, p. 251.

89) Possibilité de l'infection d'Aedes aegypti mâle par le virus de la fiêvre Jaune. C. R. Soc. Biol. 1929, 102, n. ${ }^{\circ} 26$, p. 54.

90) Sur la transmission du virus de la fièvre Jaune par les déjections de (ccm Lima, A. da Costa)

C. R. Soc. Biol., 1929, 102, n.o 26, p. 53.

91) Modernas acquisições sobre a febre amarela experimental.

Arch. de Hygiene, D.N.S.P., 1929, 3, n.o 2, p. 5.

92) Infection des Aedes aegypti mâles avec les virus de la fiévre Jaune. C. R. Soc. Biol., 1929, 102, n.o 29, p. 476.

93) Possibilité de la transmission directe de la fièvre jaune de stégomyie à stégomyie.

C. R. Soc. Biol., 1929, 102, n.o 29, p. 474.

94) Sur le temps nécessaire aux stégomyies infectées pour excréter des fèces virulentes.

(com Lima, A. da Costa)

C. R. Soc. Biol., 1929, 102, n.o 29, p. 478. 
951 Transmission de la fièvre jaune par l'application de fèces de moustiques infectés sur la peau et la muqueuse oculaire intactes.

(com Lima, A. da Costa)

C. R. Soc. Biol., 1929, 102, n. 029, p. 477.

96) Transmissão da febre amarella pelos mosquitos.

(Conferencia Bahia, 30-10-1929)

Brasil-Medico, 1929, 43, n. ${ }^{\circ} 49$, p. 1482.

97) Yellow fever virus. Transmission of Brazilian strains to Macacus rhesus and Macacus cynomolgus: preliminary report.

J.A.M.A., 1929,92, p. 550 .

98) Febre amarela experimental no Brasil.

4. ${ }^{\mathrm{a}}$ Conferencia Sul-Amer. Hyg., Microb. e Pathol., Rio, 1929, 1 parte, p. 753 .

99. Novas experiencias sobre a febre amarela.

(com Lima, A. da Costa)

Mem. Instituto Oswaldo Cruz, 1930, 23, n.o 2, p. 99.

100) Evolução dos gametos do Plasmodium falciparum (Nota preliminar).

Mem. Inst. Oswaldo Cruz, 1930, 24, n. ${ }^{\circ} 2$, p. 41.

101. Nouvelles experiences sur la fièvre jaune. Quantité de viruz chez le moustique.

(com Lima, A. da Costa)

C. R. Soc. Biol., 1930, 104, n. ${ }^{\circ} 20$, p. 619.

102 Evolução dos gametos do "Plasmodium falciparum".

Arch. Soc. Biol., Montevideo 1930, Suppl. n..$^{\circ}$;

Actas do Congresso Int. de Biologia de Montevideo 7 a 12 de outubro 1930.

103) Sôro-virus vaccinação na febre amarela.

Brasil-Medico, 1931, 45, n.o 3, p. 49.

104) Sòro-virus vaccinação na febre amarela.

Mem. Inst. Oswaldo Cruz, 1931, 25, n.o 2, p. 213.

105. Notas sobre os Ornithodoros rostratus, brasiliensis e turicata.

Mem. Inst. Oswaldo Cruz, 1931, 25, n.o 3, p. 227.

106) Pesquizas sobre Phytomonas françai.

Mem. Inst. Oswaldo Cruz, 1931, 25, n.o 4, p. 299.

107) Vaccination par le sérum et le virus dans la fièvre jaune.

C. R. Soc. Biol., 1931, 108, n.o 37, p. 1078.

1081 Pesquizas sobre Phytomonas françai.

Rev. Biol. e Hyg. S. Paulo, 1931, 2, n.o 4, p. 185.

109) Vaccinação contra a febre amarella. (Estado actual da questão).

Brasil-nedico, 1932, 46, n. 26, p. 573.

110) Vaccinação contra a febre amarela.

Brasil-Medico, 1933, 47, n.o 5, p. 75.

111) Consideraçoes sobre as hemogregarinas das aves.

Brasil-Medico, 1933, 47, n. 9, p. 149.

112 . Transmissāo da febre amarela por carrapatos.

Brasil-Medico, 1933, 47, n.o 11, p. 185.

113) Sobre os microbios da variola, alastrim e varicella.

Brasil-Medico, 1933, 47, n. ${ }^{\circ} 11$, p. 187.

114. Emploi de virus vivant dans la vaccination contre la fièvre Jaune. C. R. Soc. Biol., 1933, 112. n. 14, p. 1471.

115) Consideraçōes sobre os generos Kalimmatobacterium e Klebsiella. Brasil-Medico, 1933, 47, n.o 27, p. 473.

116) Considérations sur les hémogrégarines des oiseaux.

C. R. Soc. Biol., 1933, 113, n.o 18, p. 214.

117) Microbiolcgie de la variole, de l'alastrim et de la varicelle. C. R. Soc. Biol., 1933, 113, p. 1271.

118. Transmission de la fièvre jaune par les tiques.

C. R. Soc. Biol., 1933, 114, n. ${ }^{\circ} 29$, p. 137.

119. A propos du Kalymmato-bactérium granulomatis et des Klebsiella. C. R. Soc. Biol., 1933, 114, n. ${ }^{\circ} 34$, p. 841. 
1201 Pesquisas microbiologicas no alastrim.

Brasil-Medico, 1933, 47, n. ${ }^{\circ} 50$, p. 887.

121) Recherces microbiologiques sur l'Alastrim.

C. R. Soc. Biol., 1934, 115, n. ${ }^{\circ} 12$, p. 1345

122) Sensibilidade de algumas aves brasileiras ao Plasmodium precox.

Brasil-Medico, 1935, 49, n. 7 , p. 157.

1231 Sensibilité de quelques oiseaux bresiliens au Plasmodium precox.

C. R. Soc. Biol., 1935, 118, n. ${ }^{\circ}$, p. 931.

124) Tentativas da inoculação de lepra humana em Didelphideos.

(com Penido, J. Carlos)

Brasil-Medico, 1935, 49, n.o 12, p. 267.

125) Observações sobre os Ixodideos da Republica Argentina.

Mem. Inst. Oswaldo Cruz, 1935,30, n.o 3, p. 519.

126) Ixodidas brasileiros e de alguns paizes limitrophes.

Mem. Inst. Oswaldo Cruz, 1936, 31, n. 4, p. 759.

127) Transmissão da febre amarela sylvestre pelo Stegomyia (Aedes aegypti e pelos mosquitos da mata.

Brasil-Medico, 1937, 51, n. ${ }^{\circ} 17$, p. 497.

128. Epidemiologia prophylaxia da febre amarela

Conferencia na Soc. Med. e Cir. S. Paulo, em 11-5-1937.

129) Relatorio sobre o problema da febre amarela sylvestre em S. Paulo.

Apres. ao Secretario de Educacão e Saúde Pública de S. Paulo em 8-4-1937.

130) Observações a respeito de um foco limitado de febre amarela sylvestre no Estado de S. Paulo.

Brasil-Medico, 1938, 52, n.o 17, p. 401.

131) Nota sobre os Ixodideos da Republica Argentina.

Mem. Inst. Oswaldo Cruz, 1938, 33, n.o 2, p. 319.

132) Consideracões sobre a amebiasis.

Arquivos de Higiene, Rio, 8, n. 2, p. 401.

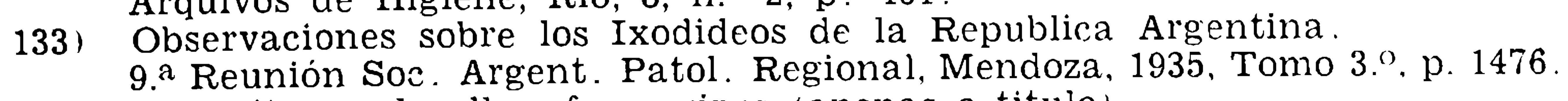

134) Mosquitos and yellow fever virus (apenas o titulo).

3erd Internat. Congr. Microbiol., 1939, N. Y., Scpt. 2-9, p. 123.

135) Relatorio sobre a situação da Lagôa Rodrigo de Freitas sob o ponto de vista biologico.

(com Penido J. Carlos N.; Santos, Mario e Oliveira, Lejeune P. H. der.

Mem. Inst. Oswaldo Cruz, 1939, 34, n. ${ }^{\circ}$, p. 457.

136) Observacões a respeito de um foco limitado de Febre Amarala Silvestre no Estado de $\mathbf{S}$. Paulo.

Mem. Inst. Oswaldo Cruz, 1939, 34, n. ${ }^{4}$ 4, p. 495.

137) Mosquitos e virus da febre amarela.

Mem. Inst. Oswaldo Cruz, 1939, 34, n. 4 , p. 547.

138) Particularidades da febre amarela urbana e da silvestre no sul do Brasil. Livro Homenagem Irmão Ozorio, 1939, p. 114.

139) Oswaldo Cruz e a Escola de Manguinhos.

Conferencia no Centro Academico Oswaldo Cruz, de S. Paulo, em 20-9-1940. p. 40 com 1 photografia.

140) Assuntos relativos a febre amarela.

A folha Medica, Rio, 1941, 22, n.o 16, p. 183.

141) Sobre a criação dos pitús (camarão ou lagosta de agua dôce).

(com Penido, J. C. \& Moreira, Cicero)

Chacaras e Quintaes, 1941, Vol. 64, n. 5 , p. 586 .

142) Sensibilidade do coelho do mato ao virus do mixoma; transmissão do mixoma pelo "Aedes scapularis" e pelo "Stegomyia".

Brasil-Medico, 1942, 56, n. ${ }^{\circ}$ 16, p. 207.

143) Ainda a criação dos pitús (camarão ou lagosta de agua dôce).

Chacaras e Quintaes, 1943, 65, n.o 5, p. 592.

144) Uma estação biológica para o estudo dos mosquitos e de outros animais silvestres relacionados com a febre amarela.

$\mathrm{Mem}$. Inst. Oswaldo Cruz, 1943, 38, n. ${ }^{\circ}$, p. 21. 
145) O virus do mixoma no coelho do mato.

Mem. Inst. Oswaldo Cruz, 1943,38, n. 1, p. 93.

146) Uma estação biológica para o estudo dos mosquitos e dos outros animais silvestres relacionados com a febre amarela.

Arq. Cir. clin. \& exper. S. Paulo, 1942, 6, n. ${ }^{\circ}$ 5/6, p. 852.

147) O virus da influenza

Actas XI Conf. sanit. Panamer., 1942. set. 7-18, p. 51.

1481 Relatorio dos trabalhos realizados durante o ano de 1942 pelo Instituto Oswaldo Cruz, apresentado ao Diretor Garal do Departamento Nacional de Saúde.

1943 , Folheto de $33 \mathrm{pp}$. com 6 fotografias.

149. Necrológico do Dr. José de Castro Teixeira.

Mem. Inst. Oswaldo Cruz, $1944,40, \mathrm{n}^{\mathrm{O}} 2$, p. I-VI.

150) Relatório dos trabalhos realizados durante o ano de 1943 pelo Instituto Oswaldo Cruz, apresentado ao Diretor Geral do Departamento Nacional de Saúde, 1944.

151) Necrologia do Dr. Astrogildo Machado.

Mem. Inst. Oswaldo Cruz, 1945, n. ${ }^{\circ}$ 2, p. I-IV.

152) Relatório dos trabalhos realizados durante o ano de 1944, pelo Instituto Oswaldo Cruz, apresentado ao Diretor Geral do Departamento Nacional de Saúde.

1945, Folheto de $66 \mathrm{pp}$. com 22 fotografias.

153) Homenagem á memória de Carlos Chagas e Evandro Chagas.

Bol. Higiene e Saúde Pública, 1946, Ano 4(6): 5-9.

154) Relatório dos trabalhos realizados durante o ano de 1945 do Instituto Oswaldo Cruz.

Rio, 1946.

155) Discurso do Dr. Henrique de Beaurepaire Rohan Aragāo.

Presidente interino do IBECC, inaugurando a Exposição de Arte Popular, da Semana Folclórica, a 22 de agôsto.

Boletim O I.B.E.C.C., 1948, 2(2): 136.

156) Nouvelles recherches sur la fièvre jaune.

Bruxelles Medical, 1928, n.o 4.

157. Relatório a respeito dos trabalhos executados na invernada dos Affonsos da Brigada Policial, apresentado ao Dr. Oswaldo Cruz (10-6-1907) .

158. Sobre o eyclo evolutivo e a transmissão do haemoproteus columbae.

Memoria apresentada ao $6 .^{\circ}$ Congresso Brasileiro de Medicina e Cirurgia. ev. Med. São Paulo, 1908, 11 (20): 416.

150. Notícia histórica sôbre a fundação do Instituto Oswaldo Cruz.

Memórias do Instituto Oswaldo Cruz, 1950, T. 48: 1-50, com 12 estampas fora do texto e uma planta.

160, Notas de ixodologia. I. Duas novas espécies do genero ixodes e um novo nome para Haemaphisalis kochi Aragão, 1908 (Acari Ixodidae).

(com Fonseca, F'lavio da)

Mem. Inst. Oswaldo Cruz, 1951, Vol. 49: 567-574.

161) Notas de exodologia. II. Uma nova espécie do gênero Amblyomma e uma nova espécie do gênero Ixodes (Acari: Ixodidae)

(com Fonseca, Flávio da)

Mem. Inst. Oswaldo Cruz, 1952, 50: 713:726. Com 2 estampas.

162. Notas de ixodologia. III. Confirmaçāo de Ixodes aragãoi Fonseca, 1935, de Ixodes amarali Fonseca, 1935, e lista das espécies do gênero Ixodes que ocorrem no Brasil (Acari, Ixodidae)

(com Fonseca, Flávio da)

163. Notas de Ixodologia. IV. Considerações sôbre a nomenclatura de algumas espécies do gênero Amblyomma do Brasil e países limítrofes. (Acari: lxodidae) (com Fonseca, Flávio dal 
164) Uma Epizootia e vários insetos sugadores úteis ao homem. A mixomatose dos coelhos na Austrália.

Manguinhos, Bol. do I.O.C., Ano 1, n.o 4. 1-4. 1952.

165) Trabalhos sôbre o Granuloma venereum.

Anaes do $1 .^{\circ}$ Congresso de Dermatologia e Syphilographia .

Rio de Janeiro, 13 a 20 de outubro, 1918: 301-305.

166) A mixomatose dos coelhos na França.

Manguinhos, Bol. I.O.C., Ano 2, n.o 9, 9-10, 1953.

167) Carlos Chagas, Diretor de Manguinhos.

Memórias do Instituto Oswaldo Cruz, Tomo 51, 1-10, 1953.

168) A propósito da validade de algumas espécies do gênero Amblyomma do continente Americano (Acari: Ixodidae).

(com Fonseca, Flávio da)

Memórias do Instituto Oswaldo Cruz, Tomo 51, 485-492, 1953.

169) VI - Descrição da fêmea de Amblyomma multipunctum Neumann 1899 e redescrição do macho (Acari: Ixodidae).

(com Fonseca, Flávio da)

Memórias do Instituto Oswaldo Cruz, Tomo 51, 493-498, 1953.

170) VII - Otocentor nitens Neumann, 1897, versus Anocentor columbianus Schulze, 1937 e comentarios sôbre a rápida disseminação dêsse Ixodideo no Brasil (Acari: Ixodidae). (com Fonseca, Flávio da) Memórias do Instituto Oswaldo Cruz, Tomo 51, 499-502, 1953.

171) O Pneumocystis carinii como causa de pneumonia intersticial em crianças. (com J. Jesuino Maciel)

Pediatria Prática, Vol. 26, n.o 1, 11-20, 1955. 